\title{
The Effects of Various Additive Components on the Sound Absorption Performances of Polyurethane Foams
}

\author{
Shuming Chen,,2 Yang Jiang, ${ }^{1}$ Jing Chen, ${ }^{1}$ and Dengfeng Wang ${ }^{1}$ \\ ${ }^{1}$ State Key Laboratory of Automotive Simulation and Control, Jilin University, Changchun 130022, China \\ ${ }^{2}$ College of Automobile Engineering, Jilin University, No. 5988 Renmin Street, Changchun 130022, China \\ Correspondence should be addressed to Dengfeng Wang; caewdf@jlu.edu.cn
}

Received 4 December 2014; Revised 18 February 2015; Accepted 27 February 2015

Academic Editor: Abbas S. Milani

Copyright (c) 2015 Shuming Chen et al. This is an open access article distributed under the Creative Commons Attribution License, which permits unrestricted use, distribution, and reproduction in any medium, provided the original work is properly cited.

\begin{abstract}
Flexible polyurethane (PU) foams comprising various additive components were synthesized to improve their acoustic performances. The purpose of this study was to investigate the effects of various additive components of the PU foams on the resultant sound absorption, which was characterized by the impedance tube technique to obtain the incident sound absorption coefficient and transmission loss. The maximum enhancement in the acoustic properties of the foams was obtained by adding fluorine-dichloroethane (141b) and triethanolamine. The results showed that the acoustic absorption properties of the PU foams were improved by adding $141 \mathrm{~b}$ and triethanolamine and depended on the amount of the water, 141b, and triethanolamine.
\end{abstract}

\section{Introduction}

The gradual increase in the undesirable and hazardous noise level has perplexed our living and working environment; therefore, noise reduction is a very important issue [1]. The use of sound absorption materials is the preferred method to reduce noise. With regard to the enhanced sound damping performance, porous materials are commonly used in various industrial applications to absorb sound energy. These porous materials have been widely used in numerous fields such as thermal insulation, building construction, aeronautics, and acoustic absorption [2-5]. These materials have played significant roles in promoting acoustic performances such as sound absorption, acoustic attenuation, and vibration damping. Lightweight porous materials such as polyurethane (PU) foams are extensively used as noise control materials in the automotive industry. The noise produced by vehicles not only affects the quality of the automobile but also decreases the comfort of driving. Eliminating automotive interior noise has become an important and predominant topic in the noise control engineering. Previous studies have investigated to improve the acoustic comfort index in motor cars [6].

$\mathrm{PU}$ is a significant sound absorbing material owing to its relatively low density and high porosity. It can be converted into ordinary soft foam, high elastic foam, or other porous materials as required in diverse applications. Viscoelastic polymer foams have excellent performance in the acoustic absorption because they can attenuate certain vibrations and absorb sound energy. Moreover, they can also convert sound and mechanical vibrational energy into heat. When acoustic waves propagate in the foams, energy is decreased as a result of the air friction loss in the cores and then transformed into heat. This energy absorption is limited by the PU morphology, which is an inherent property of the foam and is described by the gradual decrease in energy in the dissemination of the acoustic wave propagation [7]. Flexible PU foams with open cell morphology are widely used in automobiles to improve the noise, vibration, and harshness comfort [8-10]. Taking advantage of specific vibration characteristics, flexible PU foams have also been used in automotive seating applications $[9,11]$. The optimization of the acoustic performance can be accomplished in various ways, such as altering the chemical structure of the PU solid phase or adding various types of additives to the foams [12]. Hong et al. [13] studied the multiporous polymer microspheres with interconnected cavities, with appearing good sound absorption properties particularly in a low frequency range. PU/nanosilica nanocomposite foams were prepared 
by Lee et al. [1] to improve the sound absorption ability of PU foams by adding nanosilica to PU. A sandwich composite plank with polyethylene terephthalate/thermoplastic urethanes/PU in the fibrous conformation was manufactured to attain high sound absorption properties reported by Lin et al. [14]. The effects of aluminum hydroxide addition on the properties of palm-based composites were investigated by Norzali et al. [15]. Numerous studies on predicting the sound absorption performances are reported through alternative material properties including the airflow resistivity, porosity, elastic constants, and pore geometry. The airflow resistivity is a main parameter governing the acoustical behavior of porous materials for the sound absorption. The PU foams with adequate flow resistance values show good sound absorption. The airflow resistivity is the ratio of the static pressure difference between the two sides of the material to the line speed of the airflow, which stably passes through the porous material. Larger flow resistance hinders the sound waves more difficult to reach into the interior of the materials, leading to low sound absorption performance; however smaller flow resistance will less efficiently convert sound energy into thermal energy; therefore, an optimum flow resistance of the porous material is required [16]. The airflow resistivity has a close relationship with the material's pores and is also an important parameter describing the porous material's performance. The open porosity of porous foams is defined as the fraction of the interconnected pore fluid volume to the total bulk volume of the porous aggregate and is a key parameter related to the effective properties of the porous foams [17]. Doutres et al. [18] investigated the relationship between the microstructure of $\mathrm{PU}$ foams and sound absorption efficiency, and the nonacoustic properties were also measured to investigate the relationship between the microstructure properties and nonacoustic parameters.

Both the sound absorption coefficient and transmission loss are the parameters for measuring the sound absorption performance of materials. The absorption coefficient can be measured using the standard test procedures in the standard of "Standard Test Method for Impedance and Absorption of Acoustical Materials using a tube, two microphones and a digital Frequency Analysis System." Recent studies have shown the focus on the effect of these sound absorbing properties of PU foams to enhance the acoustic performances (e.g., vibration and acoustic attenuations). The sound absorption properties of the foams have been extensively studied. Zhang et al. investigate the effect of the pore cell size and open porosity on the sound absorption performance of $\mathrm{PU}$ porous materials, and experiments were performed to investigate the relationships between the geometrical characteristics of the polyurethane foams and their acoustic performances [19]. The pore size distributions and microscopic structures of the acoustic materials significantly affected the sound absorption performance. Caviglia and Morro [20] and Jung et al. [21, 22] studied the sound properties of multilayered viscoelastic foams with planar interfaces and Yang et al. [23] reported the sound properties of the multilayered viscoelastic composites with different interface shapes. Chen et al. [24] investigated the effects of the surface shapes and sizes of the porous materials with perforated plates on the acoustic absorption by using the finite element procedure. Cheng et al. [25] studied the relationship between the underwater acoustic property and the pore structure of porous aluminum and attained an optional porosity of porous aluminum with the best sound absorption. Hong et al. developed the multiporous hollow poly microspheres and found that the materials consisted of the polymer microspheres with good sound absorption [13]. Lind-Nordgren and Göransson reported a procedure to measure the sound absorption behavior of porous foams to optimize the behavior of acoustical and vibrational performances [26]. These studies are meaningful and instructional for the design of sound absorption materials. However, to the best of our knowledge, there are few investigations reported on the effects of additive components in the foams. In this study, the sound absorption is characterized by the impedance tube technique to obtain the incident sound absorption coefficients and transmission losses [27-29].

In this study, flexible PU foams consisting of various additive components have been synthesized to enhance sound absorption. The purpose of this paper was to investigate the effect of the various additive components of the PU foams on their sound absorption.

\section{Experimental}

2.1. Materials. PU foams were synthesized using isocyanate and polyether polyols or isocyanate and polyester polyols. Soft ether PU foams were synthesized to be used as the acoustic and insulation materials in automobiles. The names and major characteristics of the materials used are listed in Table 1. Polyether polyols $330 \mathrm{~N}$ with a hydroxyl value of $36 \mathrm{mg} \mathrm{KOH} / \mathrm{g}$ and polyether polyols of 3630 with an $\mathrm{OH}-$ value of 33-37 mg KOH/g were supplied by Guangzhou Yiju Chemical Company, China.

Methylenediphenyl diisocyanate (MDI) was obtained from Guangzhou Yiju Chemical Company, China. A1 and A33 were used as the amine catalysts. A1, composed of $70 \%$ bisdimethylaminoethyl ether solution in dipropylene glycol, is a "foaming" type catalyst. Moreover, A33 is composed of $33 \%$ triethylene diamine solution. Water and $141 \mathrm{~b}$ are both used for blowing agents. Triethanolamine, as the catalyst, played a dominant role in controlling the cell size of the foam. Silicone, widely used in the PU foam industry, was selected as the foam stabilizer and surfactant in this study.

2.2. Preparation of $P U$ Foams. The polyether polyols $330 \mathrm{~N}$ and 3630, surfactant, catalyst, and deionized water were weighed according to the foam formulation listed in Table 2 . First, the materials, except for MDI, were gradually weighed, added in a plastic cup, and then mixed and stirred uniformly using a mechanically driven mixer at a rotational velocity of $1200 \mathrm{rpm}$ for $60 \mathrm{~s}$. Finally, MDI was added, and the mixture was stirred for an additional 7 to $8 \mathrm{~s}$. The mixture was poured into a rectangular mold with a dimension of $150 \times 150 \times$ $60 \mathrm{~mm}^{3}$ and its temperature was fixed at $50^{\circ} \mathrm{C}$. After curing 
TABLE 1: Major characteristic of the materials.

\begin{tabular}{lcc}
\hline & Materials & Supplier \\
\hline Isocyanate & MDI & Guangzhou Yuju Chemical Co. China \\
Polyether polyol & 3630 & Guangzhou Yuju Chemical Co. China \\
Polyether polyol & $330 \mathrm{~N}$ & Guangzhou Yuju Chemical Co. China \\
Catalyst & A1 and A33 & Guangzhou Yuju Chemical Co. China \\
Catalyst & TEA & Jiahua Fushun Chemical Co. China \\
Surfactant & Silicone 8681 & Guangzhou Yuju Chemical Co. China \\
Blowing agent & $141 \mathrm{~b}$ & Guangzhou Yuju Chemical Co. China \\
\hline
\end{tabular}

TABLE 2: Foam formulation and design.

\begin{tabular}{|c|c|c|c|c|}
\hline Main component & $\begin{array}{c}\text { Group } 1 \\
\text { (parts by weight) }\end{array}$ & $\begin{array}{c}\text { Group } 2 \\
\text { (parts by weight) }\end{array}$ & $\begin{array}{c}\text { Group } 3 \\
\text { (parts by weight) }\end{array}$ & $\begin{array}{c}\text { Group } 4 \\
\text { (parts by weight) }\end{array}$ \\
\hline 3630 & 28 & 28 & 28 & 28 \\
\hline $330 \mathrm{~N}$ & 52 & 52 & 52 & 52 \\
\hline MDI & 28.8 & 28.8 & 28.8 & 28.8 \\
\hline Catalyst A1 & 0.04 & 0.04 & 0.04 & 0.04 \\
\hline Catalyst A33 & 0.9 & 0.9 & 0.9 & 0.9 \\
\hline Silicone & 0.9 & 0.9 & 0.9 & 0.9 \\
\hline
\end{tabular}

for $120 \mathrm{~min}$, the foam was removed and aged for $24 \mathrm{~h}$ at room temperature. Before the test, a cylindrical block was cut from the center of the cured foam. The cylindrical block had a thickness of $20 \mathrm{~mm}$, and the blocks with the diameters of $28 \mathrm{~mm}$ and $100 \mathrm{~mm}$ were used for high- and low-frequency tests, respectively. Figure 1 shows the process for preparing the PU foams. Figure 2 shows the sample foams used for testing.

2.3. Experimental Apparatus and Measurement Tests. The porosity $(\Phi)$ and airflow resistivity " $\sigma$ " are determined from the flow measurements. A flow resistance apparatus is devised according to the American National Standards ASTM C52280. Figure 3 shows the schematic of the apparatus. The sample is placed in a tube as shown in Figure 3, and the pressure difference $(\Delta P)$ between two sides of the sample is formed by pumping or compressing, when a steady flow of air is established. The airflow through the sample is measured and the differential pressure $(v)$ is obtained by the pressure measurement. The flow resistance is calculated by the following equation:

$$
\sigma=\frac{\Delta P}{v} .
$$

According to the study of Benkreira et al. on the porosity [30], the porosity was measured by the simple measurement device consisting of two $60 \mathrm{~mL}$ chambers and a U-tube $(5 \mathrm{~mm}$ diameter) water manometer connecting them. The chamber air pressure volume is controlled by two glass pistons of $10 \mathrm{~mL}$ capacity suitably calibrated and graduated for the accurate measurement readings. The air pressure volume in the manometer is similarly controlled using a $20 \mathrm{~mL}$ piston.
Once calibrated, the device measures the air volume of the open, interconnected pores of a porous sample placed in the measuring chamber. Figure 4 shows the layout for the test equipment for porosity.

The experimental methods according to ASTM E-1050 were used to determine the normal sound absorption performance [31]. The standard test for impedance and absorption of acoustical materials of ASTM E-1050 is based on the standard ISO 10534-2:1998(E) [32]. This test method was applied to measure the sound absorption coefficients of absorptive materials at normal incidence. The sound absorption coefficient test was performed using a two-microphone impedance tube, also called the "transfer function method." Figure 5 shows the apparatus used including the two-microphone impedance tubes for the absorption testing. The test was performed at room temperature $\left(20^{\circ} \mathrm{C}\right)$ under a relative humidity of $65 \%$. The sample diameter was $100 \mathrm{~mm}$.

The test sample is mounted at one end of a straight, rigid, smooth, and airtight impedance tube; the other end of the tube is connected to a sound source (loudspeaker). Plane waves are generated in the tube by a sound source (random, pseudorandom sequence or chirp), and the sound pressures are measured at two locations near to the sample. Sound waves propagate as the plane waves in the tube, hit the sample, get partially absorbed, and then get subsequently reflected. The test measures the sound pressure close to the sample at two different positions to obtain the acoustic transfer function of the two-microphone signals. The complex acoustic transfer function of the two-microphone signals is determined and used to compute the normal incident complex reflection factor, normal-incidence sound absorption coefficient, and transmission loss of the test material. The acoustic absorption coefficient is defined as the ratio of 


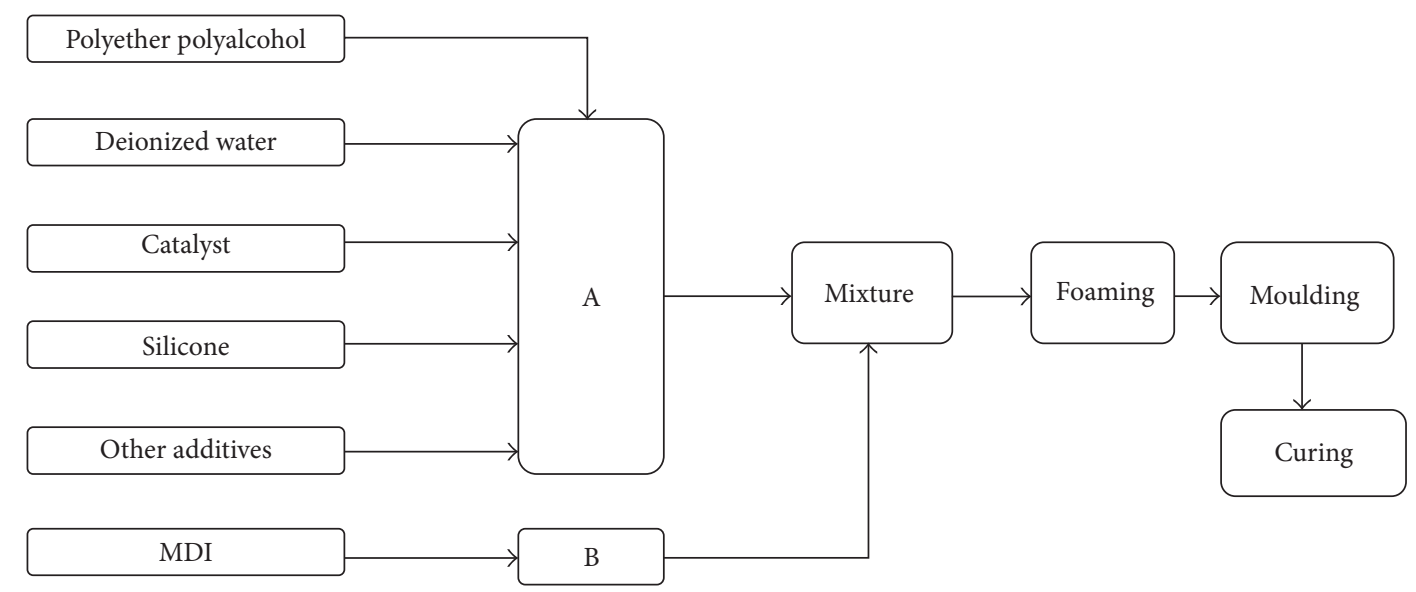

FIGURE 1: Process for preparing the polyurethane foams.
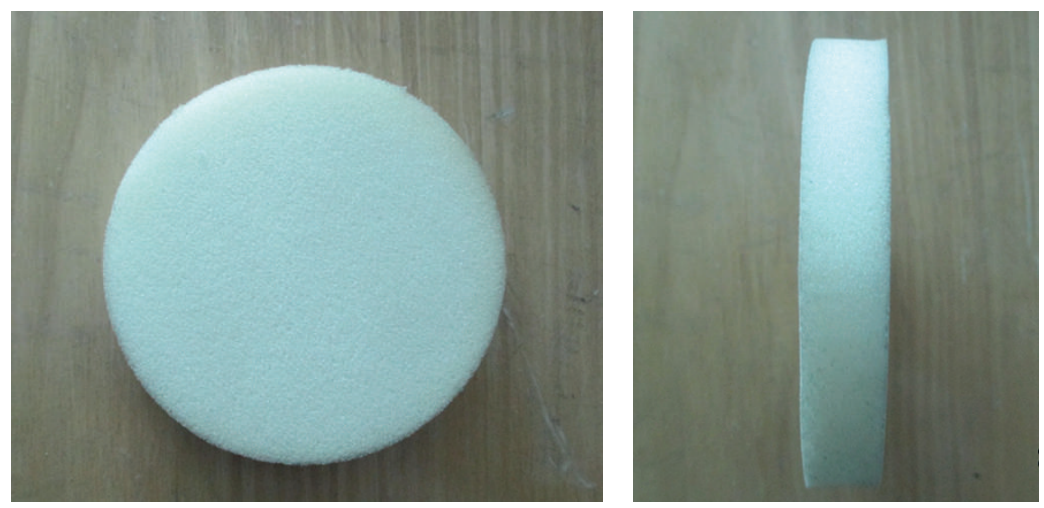

FIGURE 2: Prepared foams for testing.

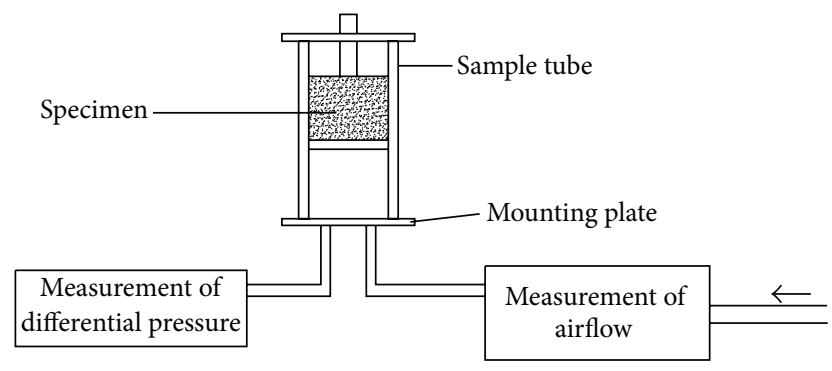

FIgURE 3: The layout for the test equipment for airflow resistance.

the acoustic energy absorbed by the foam to the acoustic energy incident on its surface, and it depends on the frequency. The absorption coefficient was calculated as the average value of the values obtained from four cylindrical foam pieces (100 $\mathrm{mm}$ in diameter and $20 \mathrm{~mm}$ in thickness) in the frequency range $100-6,000 \mathrm{~Hz}$, according to the procedure. The sound waves were perpendicular to the surface of the foams. Each of the tests was repeated at least four times to obtain consistent and precise results [19]. The densities of the foams were calculated by measuring the dimensions and weight of the foam sheets. These preliminary measurements are shown in Figure 6.

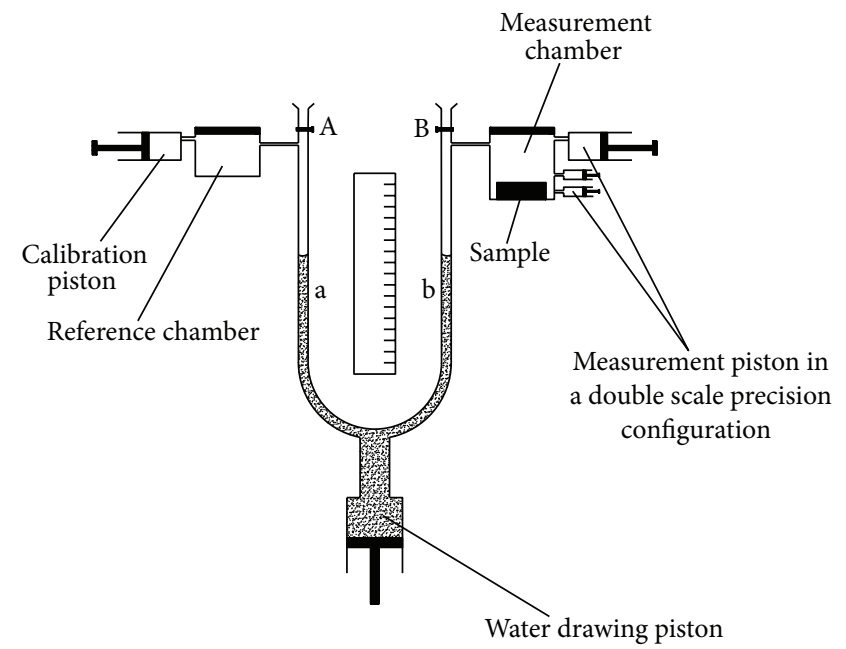

FIGURE 4: The layout for the test equipment for porosity.

\section{Results and Discussion}

In this study, water was used as the primary blowing agent as well as the chemical blowing agent in the PU, and it plays a dominant role in controlling the absorption coefficient. In the first experiment, water was added to investigate 
TABLE 3: Main components and properties of the foam.

\begin{tabular}{|c|c|c|c|c|}
\hline Main component & $\begin{array}{c}\text { Group } 1 \\
\text { (parts by weight) }\end{array}$ & $\begin{array}{c}\text { Group } 2 \\
\text { (parts by weight) }\end{array}$ & $\begin{array}{c}\text { Group } 3 \\
\text { (parts by weight) }\end{array}$ & $\begin{array}{c}\text { Group } 4 \\
\text { (parts by weight) }\end{array}$ \\
\hline 3630 & 28 & 28 & 28 & 28 \\
\hline $330 \mathrm{~N}$ & 52 & 52 & 52 & 52 \\
\hline MDI & 28.8 & 28.8 & 28.8 & 28.8 \\
\hline Catalyst A33 & 0.9 & 0.9 & 0.9 & 0.9 \\
\hline Catalyst A1 & 0.04 & 0.04 & 0.04 & 0.04 \\
\hline Silicone & 0.9 & 0.9 & 0.9 & 0.9 \\
\hline TEA & 1.0 & 1.0 & 1.0 & 1.0 \\
\hline Water & 3.8 & 4.1 & 4.4 & 4.7 \\
\hline Density $\left(\mathrm{kg} / \mathrm{m}^{3}\right)$ & 80.2 & 71.8 & 69.9 & 64.0 \\
\hline Airflow resistivity & 18,600 & 15,400 & 14,600 & 11,300 \\
\hline Porosity & 74 & 77 & 83 & 89 \\
\hline
\end{tabular}

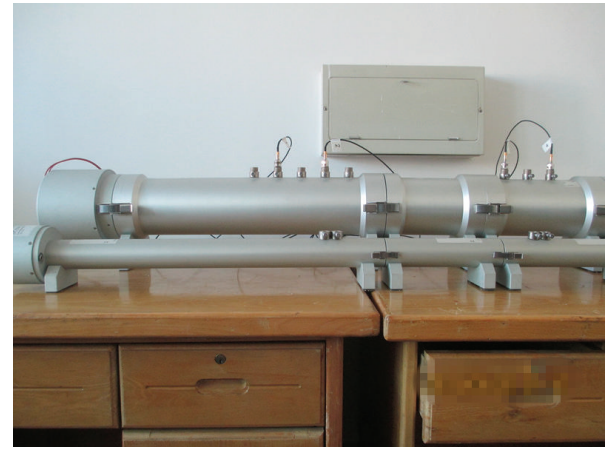

FIGURE 5: Apparatus of the two-microphone impedance tube for the ASTM-E-1050: absorption testing.

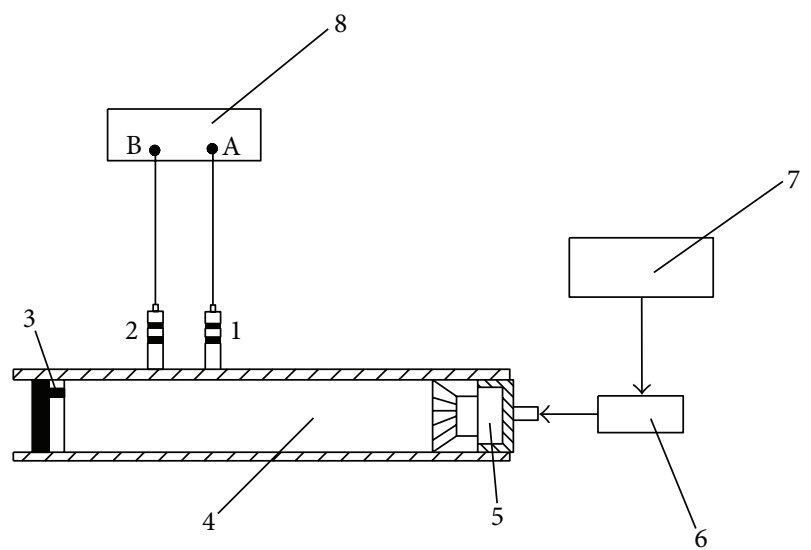

FIGURE 6: Example of the layout for the test equipment. (1) Microphone A, (2) microphone B, (3) test specimen, (4) impedance tube, (5) sound source, (6) amplifier, (7) signal generator, and (8) frequency analysis system.

the influential trends on the absorption coefficient of the PU foams according to the recipes listed in Table 3.

Figure 7 shows the sound absorption coefficient curves for the PU foams with varying water contents. With increasing water content, no obvious increase in the absorption

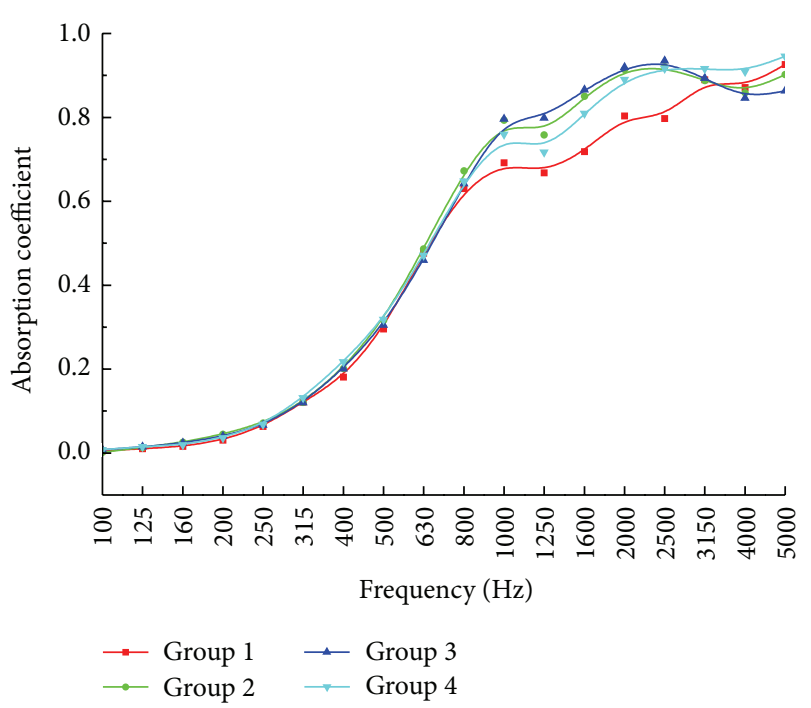

FIGURE 7: Curves showing the sound absorption character of the PU foams with varying water contents. (a) Group 1 with water 3.8 parts by weight, (b) Group 2 with water 4.1 parts by weight, (c) Group 3 with water 4.4 parts by weight, and (d) Group 4 with water 4.7 parts by weight.

coefficient in the low frequency range (100 to $800 \mathrm{~Hz}$ ) was observed. However, the absorption coefficient gradually increased in the high frequency region 1,000-5,000 Hz. The acoustic absorption coefficient of the foam with 4.7 parts by weight is obviously higher than that of the rest of the composite in the higher frequency range, particularly in the range $3,000-5,000 \mathrm{~Hz}$. When the water content was 4.4 parts by weight, the sound absorption coefficient reached a maximum of 0.935 . The graph shows that with increasing water content in a certain range, the sound absorption coefficients of the foams continue to increase. When the water content is increased to 4.7 parts by weight, the sound absorption coefficient of the foam sharply decreases. From the curves, it is seen that a bigger airflow resistivity does not result in a better performance and indicates a larger resistivity that the air suffers in the materials. Moreover, lower 
TABLE 4: Main components and properties of the foams.

\begin{tabular}{|c|c|c|c|c|}
\hline Main component & $\begin{array}{c}\text { Group } 1 \\
\text { (parts by weight) }\end{array}$ & $\begin{array}{c}\text { Group } 2 \\
\text { (parts by weight) }\end{array}$ & $\begin{array}{c}\text { Group } 3 \\
\text { (parts by weight) }\end{array}$ & $\begin{array}{c}\text { Group } 4 \\
\text { (parts by weight) }\end{array}$ \\
\hline 3630 & 28 & 28 & 28 & 28 \\
\hline $330 \mathrm{~N}$ & 52 & 52 & 52 & 52 \\
\hline MDI & 28.8 & 28.8 & 28.8 & 28.8 \\
\hline Catalyst A33 & 0.9 & 0.9 & 0.9 & 0.9 \\
\hline Catalyst A1 & 0.04 & 0.04 & 0.04 & 0.04 \\
\hline Silicone & 0.9 & 0.9 & 0.9 & 0.9 \\
\hline TEA & 1.0 & 1.0 & 1.0 & 1.0 \\
\hline $141 b$ & 5.0 & 5.0 & 5.0 & 5.0 \\
\hline Water & 3.8 & 4.1 & 4.4 & 4.7 \\
\hline Density $\left(\mathrm{kg} / \mathrm{m}^{3}\right)$ & 81.2 & 75.0 & 64.8 & 61.9 \\
\hline Airflow resistivity & 17,800 & 16,500 & 13,800 & 9,800 \\
\hline Porosity & 72 & 79 & 85 & 91 \\
\hline
\end{tabular}

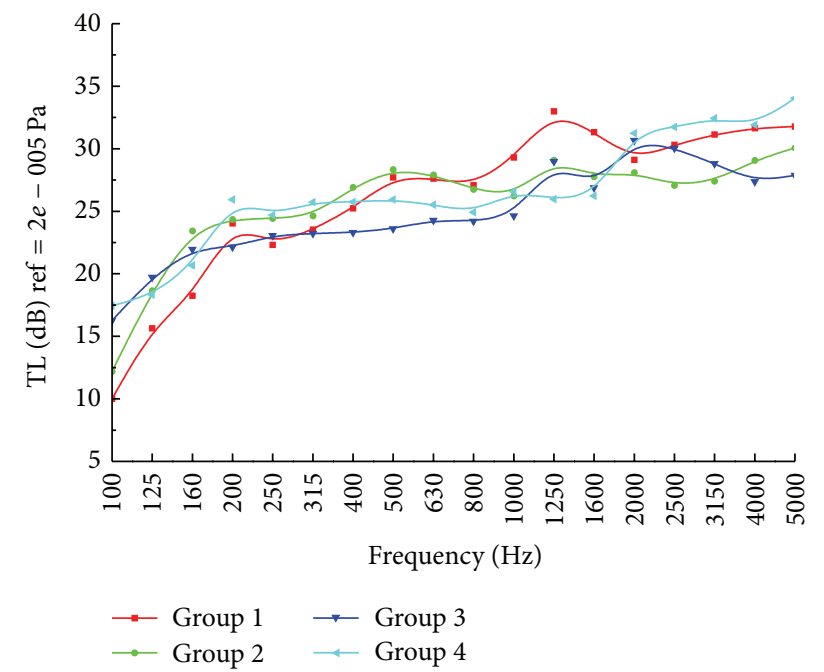

FIGURE 8: Curves of transmission loss of the PU foams with varying water contents. (a) Group 1 with water 3.8 parts by weight, (b) Group 2 with water 4.1 parts by weight (c) Group 3 with water 4.4 parts by weight, and (d) Group 4 with water 4.7 parts by weight.

resistivity value decreases the sound absorption coefficient. This is possibly because of the high water content, increasing the porosity, and lower overall density. This leads to dramatic decrease in the sound absorption. These results clearly show that the water content has a significant effect on the sound absorption properties of the foams. The corresponding curves of transmission loss are shown in Figure 8. The results are in good agreement with the sound absorption coefficient and transmission loss curves. The sound insulation properties of the porous materials appear to be in opposite trend to the sound absorption properties, and better sound absorption properties of materials decrease the sound insulation performance. When the water content is 3.8 parts by weight, the transmission loss reaches the maximum value of 32.9 , and the transmission loss also presents a downward trend with increasing water content. The PU foams with a water content of 3.8 parts by weight show better sound insulation properties compared with other three groups.

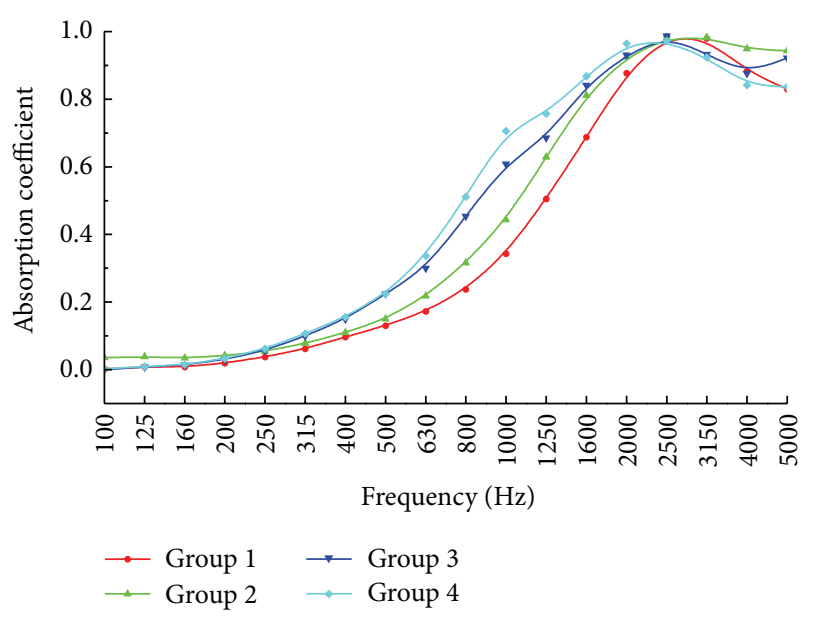

Figure 9: Curves of the sound absorption character of the PU foams with varying water with the $141 \mathrm{~b}$. (a) Group 1 with water 3.8 parts by weight, (b) Group 2 with water 4.1 parts by weight, (c) Group 3 with water 4.4 parts by weight, and (d) Group 4 with water 4.7 parts by weight.

According to the results of the above experiments, when the water content is controlled within a particular range, the sound absorption performance is improved by increasing water content. However, when the water content continued to increase, the sound absorption performance decreased. The primary reason for the change in the sound dampening is the content of water in the foams. The average porosity of the foams increases and the density becomes smaller with increasing water content. Therefore, the reasonable control of the water content is necessary to improve the sound absorption properties of the foams.

In the second experiment, the type and amount of foaming agent was changed to investigate their effects on the sound absorption properties of the foams by adding $141 \mathrm{~b}$ agent. The components and properties of the foams are listed in Table 4.

Figure 9 shows the sound absorption coefficient curves of the foams under the foaming reaction of both water and 


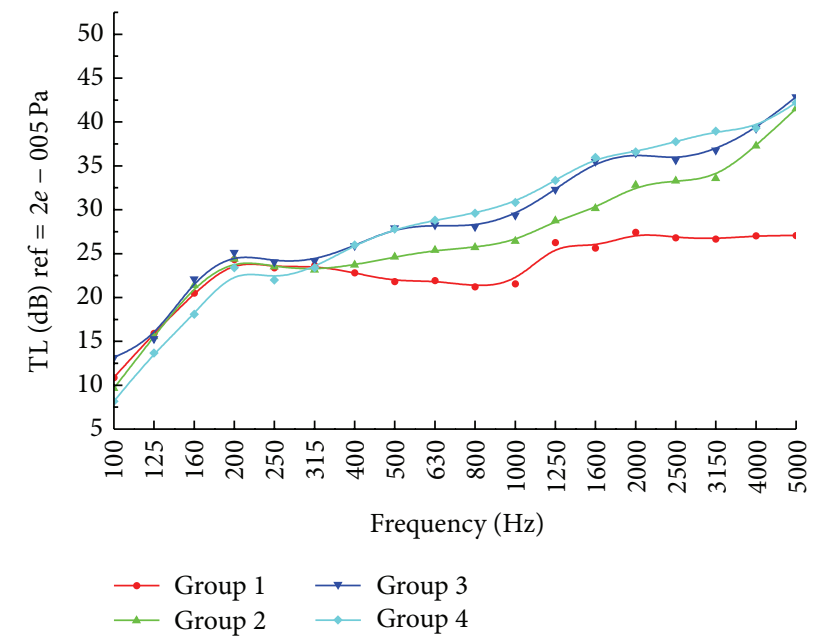

Figure 10: Curves of transmission loss of the PU foams of varying water contents and 141b. (a) Group 1 with water 3.8 parts by weight, (b) Group 2 with water 4.1 parts by weight, (c) Group 3 with water 4.4 parts by weight, and (d) Group 4 with water 4.7 parts by weight.

$141 \mathrm{~b}$ agent. As can be seen from the figure, the differences of sound absorption coefficient between various components of the material are not significant at low frequencies. However, with the increase in frequency, there is no obvious change in the sound absorption coefficient, particularly in the range $500-2,500 \mathrm{~Hz}$. The higher the water content is, the greater the absorption coefficient is. When the water content is 4.7 parts by weight and the content of $141 \mathrm{~b}$ is 1 part by weight, the sound absorption coefficient reaches maximum of 0.982 . In comparison to the results in the first experiment, the absorption coefficients of the foams increase with the amount of water. When excessive water is added to the components, a downward trend in the absorption coefficient of foams does not appear in the curves compared to the curves shown in Figure 7, indicating that $141 \mathrm{~b}$ and water commonly changed the sound absorption performances of the foams in terms of the absorption coefficient, which significantly increased the sound absorption performance of the shock absorption foam.

As shown in Figure 10, the sound insulation characteristics of the PU foams in terms of the transmission loss change with increasing frequency. However, no clear gap was observed in sound damping in the low frequency range $(100-500 \mathrm{~Hz})$, which is consistent with the same principles shown in Figure 8. The sound dampening increased $>800 \mathrm{~Hz}$, because the transmission loss increases steadily. Overall, the sound dampening improves with increasing in water concentration, as shown in Figures 8 and 10. As shown in Figure 11, the addition of $14 \mathrm{lb}$ causes bubble absorption in almost the entire frequency range. The sound absorption coefficient curve for the foams with the addition of $141 \mathrm{~b}$ is higher than the curve for foams without the addition. The results show that the average absorption coefficient increases slowly at the beginning and increases by adding 141b. The acoustic absorption coefficients of the composites with water are lower at low frequencies and much higher at high frequencies, when compared to the foams with $141 \mathrm{~b}$ additions. The results show

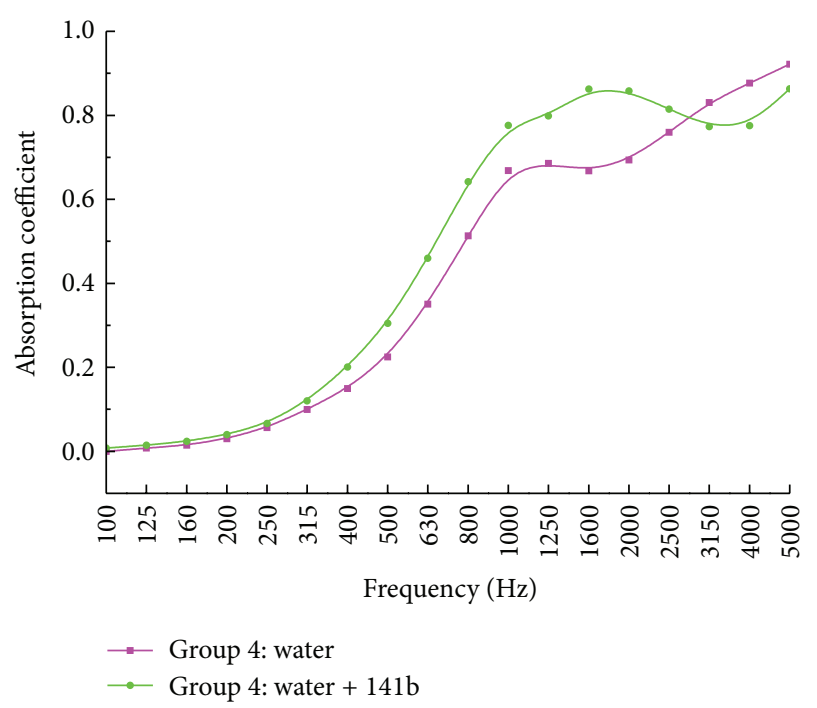

FIGURE 11: Curves of sound absorption character of the PU foams with two different compositions, one containing water without $141 \mathrm{~b}$ and the other containing water with $141 \mathrm{~b}$.

that the acoustic absorption property of the foams improved by adding $141 \mathrm{~b}$ and also depends on the quantity of water.

TEA acts as a catalyst in the reaction system. According to the effects of TEA on the foaming reaction with increasing TEA content, the foaming time decreases, and the catalytic ability to enhance the foaming reaction to produce $\mathrm{CO}_{2}$ strengthens. Meanwhile, the cell size and gas proportion both increase. When the TEA content is $<7$ parts by weight, the foaming reaction is stronger than the gel reaction. Thus, the porosity of the foams increases with increasing TEA content. This is very likely because of the domination of the crosslinking reaction. Therefore, the system can be optimized to enhance the sound absorption properties of the foam by varying the amount of TEA. As a result, in the third experiment, the amount of TEA was varied to investigate the effects on the foam performance; the major components of the materials are listed in Table 5.

Figure 12 shows the absorption coefficients when the amount of TEA in the foams was varied from 1.8 parts by weight to 2.7 parts by weight. Simultaneously, no obvious change is observed among the four groups in the low frequency range $(100-500 \mathrm{~Hz})$, but significant differences appear in the high frequency range $500-3000 \mathrm{~Hz}$. When TEA content was 2.7 parts by weight, the sound absorption coefficient reached a maximum of 0.995 . In Groups 2-4, with gradual increase in the TEA content, the absorption coefficients show a strengthening trend as a result of the increased TEA content. The amount of TEA in Group 1 is small as a result of smaller porosity than the other groups and therefore exhibits a higher density, enhancing absorption properties. The results show that an adequate amount of TEA within a certain range has a significant effect on controlling the pore size and density of the foams. The foams containing reasonable contents of TEA exhibit excellent sound absorption properties; therefore, they can be used to improve the acoustic quality of foams. 
TABLE 5: Main components and properties of the foams.

\begin{tabular}{|c|c|c|c|c|}
\hline Main component & $\begin{array}{c}\text { Group } 1 \\
\text { (parts by weight) }\end{array}$ & $\begin{array}{c}\text { Group } 2 \\
\text { (parts by weight) }\end{array}$ & $\begin{array}{c}\text { Group } 3 \\
\text { (parts by weight) }\end{array}$ & $\begin{array}{c}\text { Group } 4 \\
\text { (parts by weight) }\end{array}$ \\
\hline 3630 & 28 & 28 & 28 & 28 \\
\hline $330 \mathrm{~N}$ & 52 & 52 & 52 & 52 \\
\hline MDI & 28.8 & 28.8 & 28.8 & 28.8 \\
\hline Catalyst A33 & 0.9 & 0.9 & 0.9 & 0.9 \\
\hline Catalyst A1 & 0.04 & 0.04 & 0.04 & 0.04 \\
\hline Silicone & 0.9 & 0.9 & 0.9 & 0.9 \\
\hline $141 \mathrm{~b}$ & 5.0 & 5.0 & 5.0 & 5.0 \\
\hline Water & 3.8 & 3.8 & 3.8 & 3.8 \\
\hline TEA & 1.8 & 2.1 & 2.4 & 2.7 \\
\hline Density $\left(\mathrm{kg} / \mathrm{m}^{3}\right)$ & 81.6 & 78.3 & 74.36 & 70.5 \\
\hline Airflow resistivity & 17,100 & 16,700 & 15,200 & 14,900 \\
\hline Porosity & 74 & 82 & 87 & 89 \\
\hline
\end{tabular}

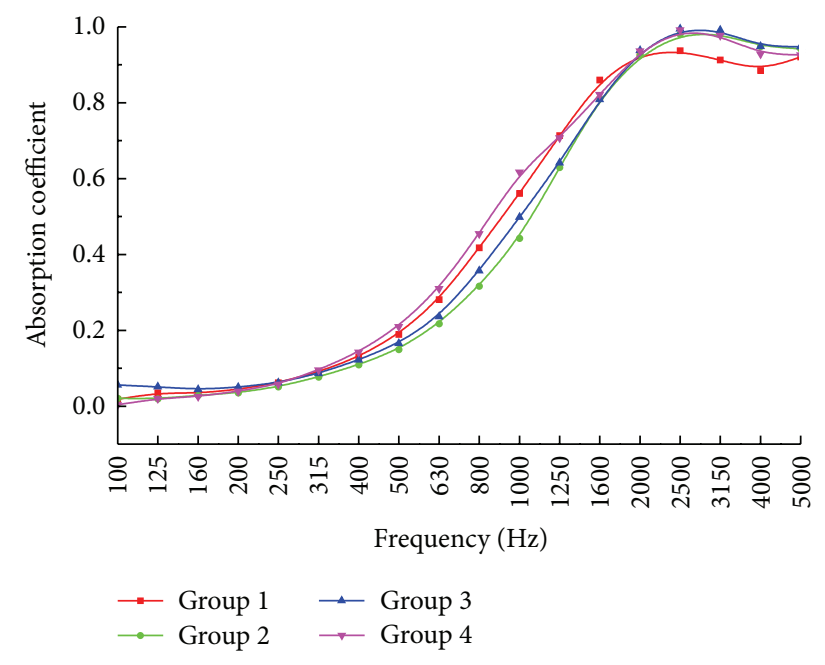

FIGURE 12: Curves of absorption coefficients of the PU foams with added triethanolamine. (a) Group 1 with 3.8 parts by weight, (b) Group 2 with 4.1 parts by weight, (c) Group 3 with 4.4 parts by weight, and (d) Group 4 with 4.7 parts by weight.

\section{Conclusions}

In this study, flexible PU foams with varying amounts of additive components were synthesized to improve sound damping and absorption. To investigate the effect of the various additive components on the sound absorption of the foams, the correlations between the contents of additive components, absorption coefficients, and transmission losses were studied. The two-microphone impedance tube was applied to measure the sound absorption and transmission loss. This study has the following conclusions:

(1) When water was used as the only blowing agent in the foams, the sound absorption properties improved with increasing water content in a certain range. When the water content was 4.4 parts by weight, the sound absorption coefficient reached a maximum of 0.935 . Excessive water will increase porosity of the foams, thus lowering its density and airflow resistivity, thereby decreasing sound absorption and dramatically increasing transmission loss.

(2) The addition of the foaming agent $141 \mathrm{~b}$ dramatically enhanced the absorption performance of the foams. When the amount of $141 \mathrm{~b}$ was 1 part by weight, an increase in water content gradually increased the sound absorption performance and reached the highest value of 0.985 without the declining trend of the curves with excessive water content. The addition of $141 \mathrm{~b}$ decreased the airflow resistivity and increased the porosity in some sense.

(3) Adding TEA has certain effects on the density of the foams and the absorption performance was enhanced. When more TEA was added, good quality foams were obtained. $141 \mathrm{~b}$ and TEA show the enhancing effects on the acoustic properties of the foams.

\section{Conflict of Interests}

The authors declare that there is no conflict of interests regarding the publication of this paper.

\section{Acknowledgments}

This study was supported by the National Natural Science Foundation project (no. 51205152), Jilin Provincial Natural Science Foundation project (20140101075JC), Specialized Research Fund for the Doctoral Program of Higher Education (20120061120036), China Postdoctoral Science Foundation Funded project (2012M520675), Jilin Province "Chunmiao" Talents Scheme, China Postdoctoral Science Foundation Funded project (2013T60322), and China Automobile (Beijing) Vehicle Lightweight Technology Institute.

\section{References}

[1] J. Lee, G.-H. Kim, and C.-S. Ha, "Sound absorption properties of polyurethane/nano-silica nanocomposite foams," Journal of Applied Polymer Science, vol. 123, no. 4, pp. 2384-2390, 2012. 
[2] R. Rodriguez, M. Estevez, S. Vargas, M. Gonzalez, R. Salazar, and F. Pacheco, "Synthesis and characterization of HAp-based porous materials," Materials Letters, vol. 63, no. 17, pp. 1558-1561, 2009.

[3] N. N. Najib, Z. M. Ariff, A. A. Bakar, and C. S. Sipaut, "Correlation between the acoustic and dynamic mechanical properties of natural rubber foam: effect of foaming temperature," Materials \& Design, vol. 32, no. 2, pp. 505-511, 2011.

[4] L. Jaouen, A. Renault, and M. Deverge, "Elastic and damping characterizations of acoustical porous materials: available experimental methods and applications to a melamine foam," Applied Acoustics, vol. 69, no. 12, pp. 1129-1140, 2008.

[5] J. P. Arenas and M. J. Crocker, "Recent trends in porous soundabsorbing materials," Sound and Vibration, vol. 44, no. 7, pp. 12$17,2010$.

[6] C. J. da Silveira Brizon and E. Bauzer Medeiros, "Combining subjective and objective assessments to improve acoustic comfort evaluation of motor cars," Applied Acoustics, vol. 73, no. 9, pp. 913-920, 2012.

[7] L. J. Gibson, “Cellular solids," MRS Bulletin, vol. 28, no. 4, pp. 270-274, 2003.

[8] Z. Lv, X. Li, and X. Yu, "The effect of chain extension method on the properties of polyurethane $/ \mathrm{SiO}_{2}$ composites," Materials and Design, vol. 35, pp. 358-362, 2012.

[9] X. Wang, J. Eisenbrey, M. Zeitz, and J. Q. Sun, "Multi-stage regression analysis of acoustical properties of polyurethane foams," Journal of Sound and Vibration, vol. 273, no. 4-5, pp. 1109-1117, 2004.

[10] I. O. Bakare, F. E. Okieimen, C. Pavithran, H. P. S. Abdul Khalil, and M. Brahmakumar, "Mechanical and thermal properties of sisal fiber-reinforced rubber seed oil-based polyurethane composites," Materials \& Design, vol. 31, no. 9, pp. 4274-4280, 2010.

[11] R. Verdejo, R. Stämpfli, M. Alvarez-Lainez et al., "Enhanced acoustic damping in flexible polyurethane foams filled with carbon nanotubes," Composites Science and Technology, vol. 69, no. 10, pp. 1564-1569, 2009.

[12] A. Andersson, S. Lundmark, A. Magnusson, and F. H. J. Maurer, "Vibration and acoustic damping of flexible polyurethane foams modified with a hyperbranched polymer," Journal of Cellular Plastics, vol. 46, no. 1, pp. 73-93, 2010.

[13] Z. Hong, L. Bo, and H. Guangsu, "Sound absorption behavior of multiporous hollow polymer micro-spheres," Materials Letters, vol. 60, no. 29-30, pp. 3451-3456, 2006.

[14] J.-H. Lin, C.-M. Lin, C.-C. Huang, C.-C. Lin, C.-T. Hsieh, and Y.-C. Liao, "Evaluation of the manufacture of sound absorbent sandwich plank made of PET/TPU honeycomb grid/PU foam," Journal of Composite Materials, vol. 45, no. 13, pp. 1355-1362, 2010.

[15] N. R. A. Norzali, K. H. Badri, and M. Z. Nuawi, "Loading effect of aluminum hydroxide onto the mechanical, thermal conductivity, acoustical and burning properties of the palmbased polyurethane composites," Sains Malaysiana, vol. 40, no. 7, pp. 737-742, 2011.

[16] X. L. Wang and T. J. Lu, "Optimized acoustic properties of cellular solids," The Journal of the Acoustical Society of America, vol. 106, no. 2, pp. 756-765, 1999.

[17] M. A. Biot, "Theory of propagation of elastic waves in a fluidsaturated porous solid. I. Low-frequency range," The Journal of the Acoustical Society Of America, vol. 28, pp. 168-178, 1956.
[18] O. Doutres, N. Atalla, and K. Dong, "Effect of the microstructure closed pore content on the acoustic behavior of polyurethane foams," Journal of Applied Physics, vol. 110, no. 6, Article ID 064901, 2011.

[19] C. Zhang, J. Li, Z. Hu, F. Zhu, and Y. Huang, "Correlation between the acoustic and porous cell morphology of polyurethane foam: effect of interconnected porosity," Materials \& Design, vol. 41, pp. 319-325, 2012.

[20] G. Caviglia and A. Morro, "Reflection and transmission in anisotropic dissipative multilayers," European Journal of Mechanics A. Solids, vol. 21, no. 6, pp. 1055-1067, 2002.

[21] K.-I. Jung, S. W. Yoon, S.-J. Sung, and J.-K. Park, "Carbon black effect on the acoustic properties of nitrile butadiene rubber," Journal of Applied Polymer Science, vol. 94, no. 2, pp. 678-683, 2004.

[22] K.-I. Jung, S. W. Yoon, K. Y. Cho, and J.-K. Park, "Acoustic properties of nitrile butadiene rubber for underwater applications," Journal of Applied Polymer Science, vol. 85, no. 13, pp. 2764-2771, 2002.

[23] X. Yang, Y. Wang, and H. Yu, "Sound performance of multilayered composites," Materials and Manufacturing Processes, vol. 22, no. 6, pp. 721-725, 2007.

[24] W.-H. Chen, F.-C. Lee, and D.-M. Chiang, "On the acoustic absorption of porous materials with different surface shapes and perforated plates," Journal of Sound and Vibration, vol. 237, no. 2, pp. 337-355, 2000.

[25] G. P. Cheng, D. P. He, and G. J. Shu, "Underwater sound absorption property of porous aluminum," Colloids and Surfaces A: Physicochemical and Engineering Aspects, vol. 179, no. 2-3, pp. 191-194, 2001.

[26] E. Lind-Nordgren and P. Göransson, "Optimising open porous foam for acoustical and vibrational performance," Journal of Sound and Vibration, vol. 329, no. 7, pp. 753-767, 2010.

[27] C. H. Sung, K. S. Lee, S. M. Oh, J. H. Kim, M. S. Kim, and H. M. Jeong, "Sound damping of a polyurethane foam nanocomposite," Macromolecular Research, vol. 15, no. 5, pp. 443-448, 2007.

[28] H. Zhou, B. Li, and G. S. Huang, "Sound absorption characteristics of polymer microparticles," Journal of Applied Polymer Science, vol. 101, no. 4, pp. 2675-2679, 2006.

[29] T. Yamashita, K. Suzuki, H. Adachi, S. Nishino, and Y. Tomota, "Effect of microscopic internal structure on sound absorption properties of polyurethane foam by X-ray computed tomography observations," Materials Transactions, vol. 50, no. 2, pp. 373-380, 2009.

[30] H. Benkreira, A. Khan, and K. V. Horoshenkov, "Sustainable acoustic and thermal insulation materials from elastomeric waste residues," Chemical Engineering Science, vol. 66, no. 18, pp. 4157-4171, 2011.

[31] ASTM International, "Standard test method for impedance and absorption of acoustical materials using a tube, two microphones and a digital frequency analysis system," ASTM E-105098, ASTM International, West Conshohocken, Pa, USA, 2012.

[32] ISO, "Acoustics-determination of sound absorption coefficient and impedance in impedance tube: part 2. Transfer-function method," ISO 10534-2, 2001. 

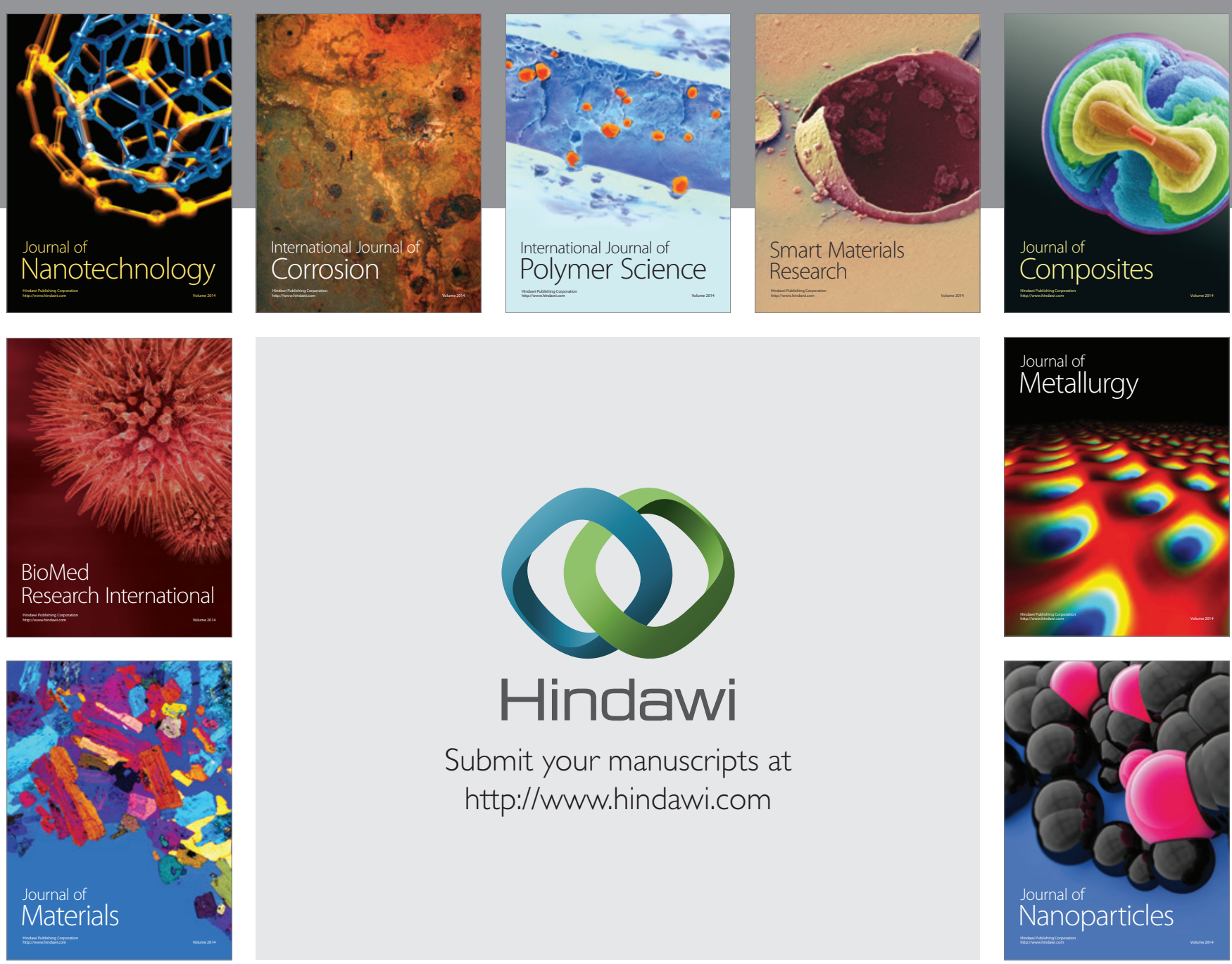

Submit your manuscripts at http://www.hindawi.com
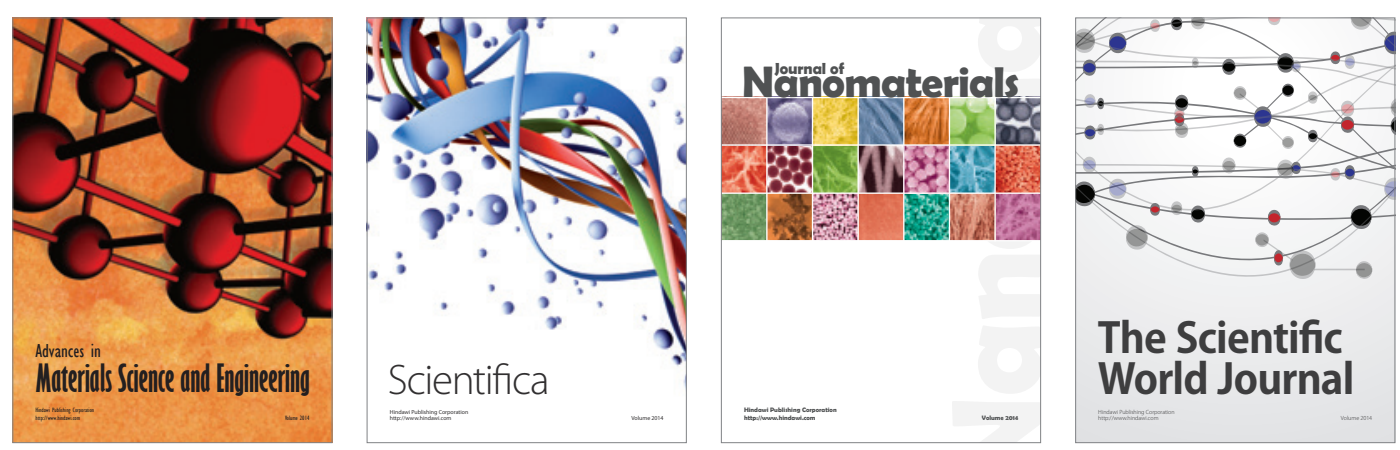

\section{The Scientific World Journal}
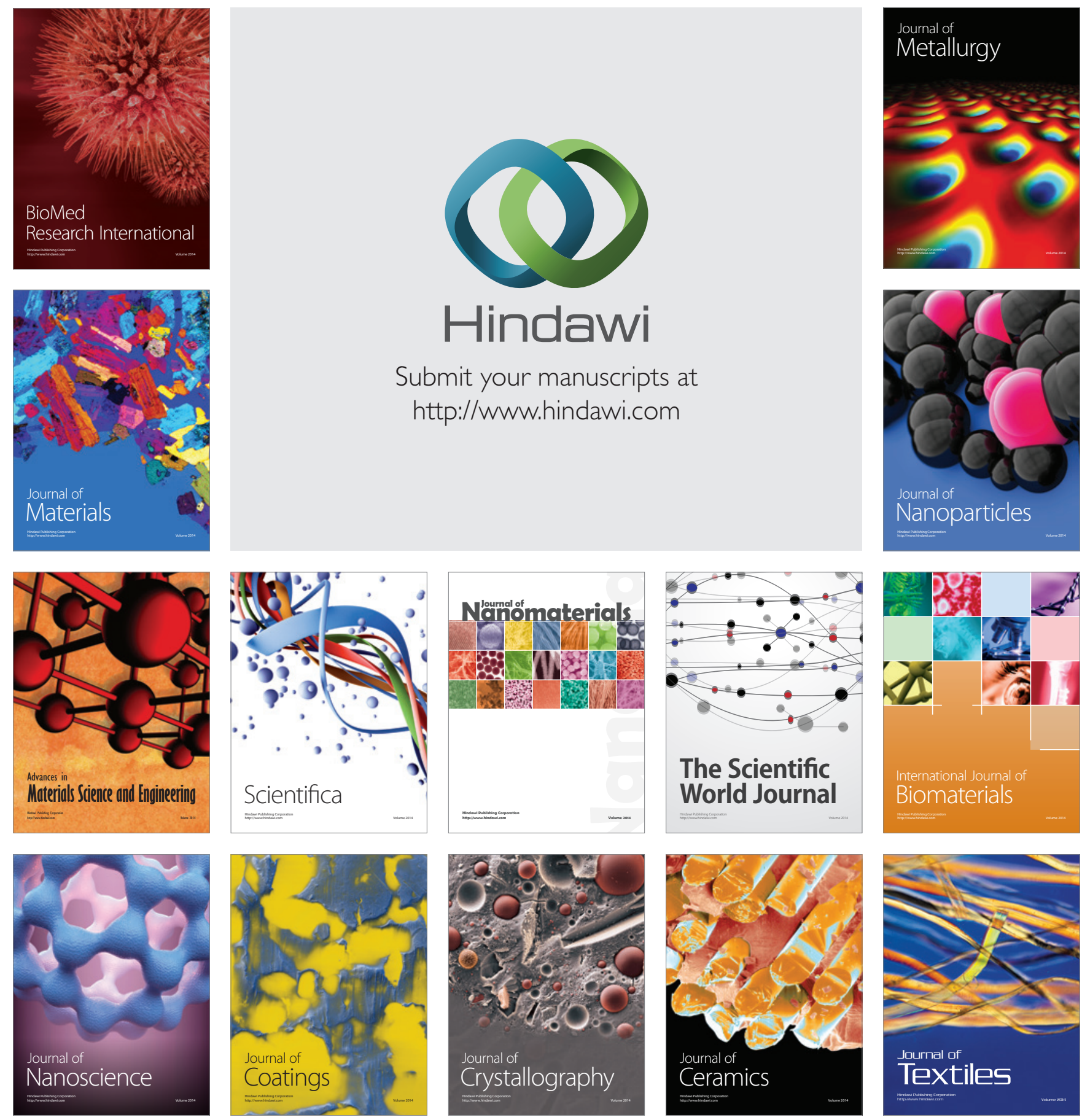